\title{
Color-contingent aftereffects on relative dominance
}

\author{
BARRY MAPPERSON \\ University of Tasmania, Hobart, Tasmania, Australia \\ and \\ WILLIAM LOVEGROVE \\ University of Wollongong, Wollongong, New South Wales, Australia
}

\begin{abstract}
The relative dominance of percepts in an ambiguous stimulus can be altered by adaptation to an unambiguous stimulus. The present paper demonstrates that this, like other negative aftereffects, can be made color-contingent.
\end{abstract}

Inspection of an unambiguous stimulus can affect our later perception of an ambiguous stimulus. Most frequently, any percept that resembles the unambiguous stimulus becomes less dominant-that is, it is less likely to be the first seen, and it is seen for a smaller proportion of the viewing period (Wallach, 1935). ${ }^{1}$ This negative aftereffect, like those of orientation, spatial frequency, and motion, has typically been assumed to be due to the fatiguing of neural mechanisms. This interpretation seems highly plausible when one is dealing with such simple stimuli as those involved in binocular or monocular rivalry between crossed gratings (e.g., Blake \& Overton, 1979; Kakizaki, 1950a, 1950b; Mapperson \& Lovegrove, 1978), although Harris (1980) has drawn attention to the fact that some cases may be more appropriately interpreted in terms of the creation of a bias in a central process.

It has been shown that negative aftereffects of color can be made contingent upon the test-stimulus orientation (McCollough, 1965), spatial frequency (Lovegrove \& Over, 1972), or direction of motion (Hepler, 1968), and that, conversely, negative aftereffects of orientation (Held \& Shattuck, 1971), spatial frequency (Virsu \& Haapasalo, 1973), and motion (Favreau, Emerson, \& Corballis, 1972) can be made contingent on the color of the test stimulus. In the present experiment, we investigated whether the negative aftereffect of adaptation on relative dominance could also be made color-contingent.

\section{METHOD}

\section{Subjects}

Twelve volunteers screened for abnormalities in color vision on the Ishihara test for color blindness participated.

\section{Apparatus and Procedure \\ Stimuli were presented to subjects by means of a projection tachisto- scope in a dimly lit room (average luminance less than $1 \mathrm{~cd} / \mathrm{m}^{2}$ ). At}

Correspondence may be sent to William Lovegrove, Department of Psychology, University of Wollongong, P.O. Box 1144, Wollongong, NSW 2500, Australia. the viewing distance of $114 \mathrm{~cm}$, all stimuli had a spatial frequency of $5 \mathrm{c} / \mathrm{deg}$ within the $4^{\circ}$ diameter field. The test stimulus was a composite of slides of a vertical and a horizontal medium-contrast (0.4) sine-wave grating. This was presented to each subject under two conditions: projected through a red filter, and projected through a green one. (As in all subsequent references, red and green refer to Wratten Nos. 26 and 55, respectively). After two practice trials, the subjects provided 1230 -sec baseline measures of relative dominance: 6 with the composite test stimulus viewed in red light, and 6 with it viewed in green. A further 1230 -sec postadaptation measures (6 for each color) were later obtained.

Prior to each of these, the subjects were exposed to vertical and to horizontal high-contrast $(0.7)$ square-wave gratings, alternated every 5 sec: one projected through a red filter, and the other through a green one. Six subjects were exposed to red vertical gratings alternating with green horizontal (RV:GH) and the other six were shown green vertical gratings alternating with red horizontal (GV:RH). The adaptation period prior to the first postadaptation trial was $120 \mathrm{sec}$; for subsequent trials, it was $60 \mathrm{sec}$. There was a 2 -sec dark interstimulus interval between the adaptation and test periods. The space-average luminance of the adaptation stimuli was $14 \mathrm{~cd} / \mathrm{m}^{2}$, and that of the composite test stimulus was $7 \mathrm{~cd} / \mathrm{m}^{2}$. Viewing was binocular throughout, and the presentation order of the test conditions was counterbalanced between subjects.

\section{RESULTS AND DISCUSSION}

The mean $\mathrm{H}-\mathrm{V}$ difference in seconds/minute was calculated for both the pre- and postadaptation conditions for each color. Table 1 shows the changes in relative dominance as a function of test-stimulus color for each group. It will be seen that there is a tendency for horizontal dominance to increase when the test stimulus is in the same color as the vertical adapting stimulus, and for horizontal dominance to decrease when the target is in

Table 1

Changes in Relative Dominance (H-V in sec/min) from Pre- to Posttest

\begin{tabular}{ccc}
\hline \multirow{2}{*}{ Adaptation } & \multicolumn{2}{c}{ Test-Stimulus Color } \\
\cline { 2 - 3 } Condition & Red & Green \\
\hline RV:GH & 10.35 & -7.08 \\
GV:RH & -6.55 & 9.19 \\
\hline
\end{tabular}

Note- RV:GH = red vertical gratings : green horizontal gratings; $\mathrm{GV}: \mathrm{RH}=$ Green vertical gratings : red horizontal gratings. 
the color of the horizontal adapting stimulus. An analysis of variance showed the interaction between adaptation condition and test-stimulus color to be significant $[F(1,5)=9.06, p<.02]$, demonstrating that the direction in which changes in relative dominance occur can, like other forms of negative aftereffects, be made contingent upon color, at least when relatively simple stimuli are involved.

\section{REFERENCES}

BLAKE, R., \& OVERTON, R. (1979). The site of binocular rivalry suppression. Perception, 8, 143-152.

Epstein, W., \& Shazo, D. D. (1961). Recency as a function of perceptual oscillation. American Journal of Psychology, 74, 215-223.

EPSTEIN, W., \& Rock, I. (1960). Perceptual set as an artifact of recency. American Journal of Psychology, 73, 214-228.

Farrow, B. J., \& Santos, J. F. (1962). A note on recency and perception. American Journal of Psychology, 75, 671-673.

Favreau. O. E., Emerson, V. F., \& Corballis, M. C. (1972). Motionperception: A color-contingent aftereffect. Science, 1, 78-79.

HARRIS, J. P. (1980). How does adaptation to disparity affect the perception of reversible figures? American Journal of Psychology, 93, 445-457.

HAyes, W. N., \& AberdeEn, J. S. (1986). Recency and the resolution of perceptual ambiguity. Bulletin of the Psychonomic Society, 24, 335. (Abstract No. 175)
Held, R., \& Shattuck, S. R. (1971). Color- and edge-sensitive channels in the human visual system: Tuning for orientation. Science, 174, 314-316.

HEPLER, N. (1968). Color: A motion-contingent aftereffect. Science, 162. 376-377.

KAKIZAKI, S. (1950a). The effects of preceding conditions upon binocular rivalry (I). Japanese Journal of Psychology, 20(2), 24-32.

KAKIZAKI, S. (1950b). The effects of preceding conditions upon binocular rivalry (II). Japanese Journal of Psychology, 20(4), 11-17.

LOVEGRove, W. J., \& OVER, R. (1972). Color adaptation of spatial frequency detectors in the human visual system. Science, 176, 541-543.

MAPPERSON, B., \& LoVEgROVE, W. (1978). Spatial frequency and orientation specificity of simultaneous and successive inhibition on monocular rivalry. Vision Research, 18, 1461-1463.

McCollough, C. (1965). Color adaptation of edge-detectors in the human visual system. Science, 149, 1115-1116.

Virsu, U., \& HaAPasalo, S. (1973). Relationships between channels for colour and spatial frequency in human vision. Perception, 2, 31-40.

WaLLACH, H. (1935). Über visuell wahrgenommene Bewegungsrichtung. Psychologische Forschung, 20, 325-380.

\section{NOTE}

1. Cases where this procedure has made a percept more dominant (Epstein \& Shazo, 1961; Epstein \& Rock, 1960; Hayes \& Aberdeen, 1986) appear to be limited to unusual and highly specific conditions (c.f. Farrow \& Santos, 1962).

(Manuscript received November 8, 1988.) 